\title{
Especificidades de nem coordenativo em português europeu ${ }^{1}$ Nádia Canceiro, Gabriela Matos, Madalena Colaço
}

Faculdade de Letras da Universidade de Lisboa, Centro de Linguística da Universidade de Lisboa

\begin{abstract}
:
European Portuguese nem corresponds to two different categories, a coordenative conjunction and a negative non-conjunctional element that in some contexts assumes a scalar meaning. We will show that, although both of these homonymous particles necessarily occur in negative domains, they have a different syntactic distribution and display specific properties. Focusing on coordenative nem in correlative and the non-correlative constructions, we will propose an account of their licensing conditions in integrated and parenthetical coordinate structures.
\end{abstract}

Keywords: nem, coordination, negation, negative polarity, coordinative conjunction

Palavras-chave: nem, coordenação, negação, polaridade negativa, conjunção coordenativa

\section{Introdução - objeto de estudo e objetivos}

Na literatura sobre o português europeu (PE), a partícula nem tem sido caracterizada como uma conjunção coordenativa negativa (Matos, 2003a; Matos \& Raposo, 2013; Peres, 2013), simples (veja-se (1a)) ou correlativa (veja-se (1b)), e como um elemento negativo não conjuncional, (2), que pode ocorrer, entre outros contextos (cf. Matos 2003b, Peres 2013), em expressões de focalização e ser intensificado pela expressão sequer, $(2 b)^{2}$ :

(1) a. «Não admito sim nem admito não», declarou ao Público Francisco Assis.

(CETEMPúblico 1.7 v. 7.7, par=ext552739-pol-97b-2)

b. (...) nem a personagem de Bob Roberts chega a ter existência autónoma nem as outras chegam a passar do estádio de simples esboços ou caricaturas. (idem, par=ext250712-clt-93a-2)

(2) a. À manifestação nem faltou uma estátua da Virgem. (idem, par=ext868353-pol-95b-2)

b. Quanto a queijos, nem sequer se pode dizer bem ou mal: só estava presente o açoreano. (idem, par=ext624-clt-soc-92a-1)

\footnotetext{
${ }^{1}$ Este trabalho foi desenvolvido no Centro de Linguística da Universidade de Lisboa (CLUL), unidade de I\&D financiada pela Fundação para a Ciência e a Tecnologia (UID/LIN/00214/2013). Agradecemos os comentários que nos foram feitos durante o XXXIII Encontro Nacional da Associação Portuguesa de Linguística, bem como os comentários e as sugestões dos revisores da primeira versão deste texto. ${ }^{2}$ No presente artigo limitar-nos-emos aos casos em que nem não-conjuncional pode coocorrer com sequer. Embora em muitos contextos, sequer possa entrar em variação livre com mesmo (cf. (i)), noutros, a substituição de sequer por mesmo produz resultados pouco aceitáveis (cf. (ii)), mostrando que não têm exatamente a mesma distribuição:

(i) À manifestação nem sequer/ mesmo faltou uma estátua da Virgem.

(ii) O jornalista terminou a reportagem e nem sequer/?? mesmo publicou as fotografias do evento.
} 
Tendo em conta este duplo estatuto de nem, consideramos necessário proceder a uma análise mais aprofundada das características desta partícula. Os exemplos em (3) ilustram o comportamento de nem não conjuncional em estruturas coordenadas, em que coocorre com uma conjunção coordenativa ${ }^{3}$.

(3) a. Não atendia o telefone, não respondia ao correio e nem abria a porta (...) ".

(CETEMPúblico, par=ext294057-clt-95b-2)

b. O Rui não escreveu os artigos ontem, porque não teve tempo ou nem se preocupou com isso. (Oliveira 2011:55)

c. A Ana quer viajar até Florença mas nem se atreve a comprar bilhetes de avião, pois tem medo de voar. (Oliveira 2011:55)

Por outro lado, nem conjuncional (4a) e nem não conjuncional (4b) partilham a característica de a sua ocorrência estar restringida a domínios frásicos negativos, propriedade que evidencia a sua semelhança. Como (5) mostra, esta propriedade está igualmente presente em frases parentéticas:

(4) a. O jornalista * $(\underline{\text { não }})$ terminou a reportagem nem publicou as fotografias do evento.

b. Ele * (não) cumprimentou nem sequer o Primeiro Ministro. ${ }^{4}$.

(5) A dificuldade da tarefa está em que Helmut Kohl * (ñão) pode (em quer) dar a imagem de que está a ceder ao veto do primeiro-ministro John Major a Jean-Luc Dehaene (...).

(CETEMPublico, par=ext801530-pol-94b-3).

Este trabalho tem, por isso, como principais objetivos (i) delimitar as propriedades de nem conector coordenativo e determinar como se relacionam com o item de negação não conjuncional que pode ocorrer na expressão nem sequer; e (ii) identificar o modo de legitimação de nem em estruturas coordenadas integradas e em estruturas coordenadas parentéticas.

A análise apresentada neste trabalho será baseada em dados disponíveis na literatura sobre o PE e, quando relevante, será confrontada com propostas avançadas para o espanhol. Além disso, ainda que de forma não exclusiva, serão apresentados dados de corpora retirados do CETEMPúblico (CETEMPúblico 1.7 v. 7.7).

\section{Contextos de ocorrência de nem}

A partícula nem pode ocorrer em diversos contextos. De seguida, apresentar-se-ão contextos de ocorrência de nem enquanto conjunção coordenativa e enquanto elemento de negação não conjuncional, bem como alguns contextos em que se considera que o estatuto de nem é ambíguo.

\footnotetext{
${ }^{3}$ Note-se que os dois tipos de nem podem coocorrer, desde que sequer seja explicitado e a expressão nem sequer enfatizada: (i) Não atendia o telefone, não respondia ao correio nem NEM SEQUER abria a porta.

${ }^{4}$ Como veremos na (secção 3.1), nem (sequer), quando tem escopo sobre o verbo flexionado da frase, por si só nega a frase: (i) O jornalista terminou a tarefa mas nem publicou as fotografias do evento.

(ii) Ele cumprimentou toda a gente e nem sequer o Primeiro Ministro escapou.
} 


\subsection{Contextos de ocorrência de nem conjunção coordenativa}

Por acumular um valor semântico aditivo e negativo, é frequente considerar-se que a conjunção coordenativa nem é semanticamente equivalente a "e não" e que a conjunção coordenativa correlativa nem...nem é equivalente a "não...e...não", vejam-se os exemplos seguintes:

(6) a. Eles não ficam em casa nem vão cinema.

b. Eles não ficam em casa e não vão ao cinema.

(7) a. Nem o João é burro nem o António é pateta.

b. O João não é burro e o António não é pateta.

(Matos \& Raposo 2013: 1792)

No entanto, em certos contextos, nomeadamente quando os elementos coordenados são sintagmas nominais ou preposicionais, a substituição de nem pelos seus equivalentes semânticos não é possível ${ }^{5}$ :

(8) a. Eu não vi a Teresa nem a Maria.

b. *Eu não vi a Teresa e não a Maria.

(9) a. Eu não trabalho nem ao sábado nem ao domingo.

(Matos \& Raposo 2013: 1792)

b. *Eu não trabalho (não) ao sábado e não ao domingo.

Assim, os exemplos em (8) e (9) mostram que, apesar de a substituição de nem por "e não" ser possível em alguns casos, tal não se verifica em todos os contextos.

Quanto ao valor de nem coordenativo, este item nem sempre apresenta valor aditivo podendo, em alguns casos, assumir um valor alternativo (cf. Matos 2003, Peres 2013), como se observa nos exemplos (10) e (11):

(10) a. Não sei se ficonem se parto.

b. Não sei se fico ou se parto.

(11) a. ...não se sentiam inspirados nem pela pátria nem pela morte. (par=ext1296549-nd-95a-1)

b. ...não se sentiam inspirados pela pátria ou pela morte.

Porém, embora a conjunção coordenativa nem possa apresentar, a par do aditivo, um valor alternativo, só é comutável com ou, e não com ou não:

(12) a. Não sei se fico em casa nem se vou ao cinema.

b. *Não sei se fico em casa ou não se vou ao cinema.

(13) a. Não se sentiam inspirados nem pela pátria nem pela morte.

b. *Não se sentiam inspirados (으 não) pela pátria ou não pela morte.

Assim, os exemplos (12) e (13) mostram que a substituição de nem, quando possui um valor alternativo, por um equivalente semântico é possível, mas com restrições, dependendo do contexto em que a partícula ocorre.

\footnotetext{
${ }^{5}$ Antecipando um pouco a análise da secção 5, convém notar que nas locuções coordenativas correlativas, apenas a última ocorrência da locução funciona como conjunção. A primeira instância da locução correlativa tipicamente marca o início do primeiro termo coordenado.
} 


\subsection{Contextos de ocorrência de nem (sequer) não conjuncional}

Além do contexto referido na secção anterior em que ocorre como conjunção coordenativa negativa, a partícula nem pode corresponder a um elemento negativo não conjuncional, podendo neste caso coocorrer com sequer, em estruturas não coordenadas ou coordenadas, como nos exemplos seguintes, respetivamente:

(14) a. «a Liga nem sequer pode comprovar que de facto está a ser feito um inquérito (par=ext311soc-91b-1)

b. Optou pela pedagogia nos contactos que teve com os sinistrados e nem sequer esqueceu a sua experiência como autarca (par=ext577-soc-98b-1)

De acordo com Matos (2003b), nestes casos, mesmo quando a partícula sequer está omitida, nem mantém o valor que tem na expressão nem sequer. Assim, em (15) e (16), o valor dos exemplos em (a) é igual ao dos exemplos apresentados em (b):

(15) a. (...) e dizem sempre que nem têm quem os oriente.

$$
\text { (par=ext807832-pol-93a-2) }
$$

b. (...) e dizem sempre que nem sequer têm quem os oriente.

(16) a. Quer dizer, no fim do despacho do processo este é dado como «subtracção ou nem isso». (par=ext1007915-soc-94a-1)

b. Quer dizer, no fim do despacho do processo este é dado como «subtracção ou nem sequer isso».

Com efeito, os exemplos (14a), (15) e (16) mostram que a ocorrência de nem em contextos que não são de coordenação é possível, e que, nesses contextos, a partícula mantém o valor que obtém quando associada ao elemento sequer, mesmo que este não esteja presente.

\subsection{Ambiguidade entre nem coordenativo e nem (sequer) item negativo não conjuncional}

Apesar de ser possível distinguir nem coordenativo de nem elemento de negação não conjuncional, tendo em conta o tipo de construção em que cada um surge, quando ocorrem em estruturas de coordenação, nem sempre é fácil distinguir os dois tipos de nem. Vejam-se, como exemplos, (17) e (18), em que nem pode ser alvo de uma interpretação com valor aditivo ou alternativo, ou com o valor do elemento que coocorre com sequer.

a. A aquisição de um computador, por exemplo, já não é uma operação fácil nem simples. (par=ext898670-clt-soc-94a-4) $\downarrow$

b. Interpretação 1: ... já não é uma operação fácil e/ou simples.

c. Interpretação 2: ...já não é uma operação fácil nem sequer simples.

(18) a. São centenas de casas erguidas entre os pinheiros, uma parte junto à margem da lagoa, sem esgotos, nem electricidade. (par=ext57761-pol-93a-2) $\downarrow$

b. Interpretação 1: ...sem esgotos, e/ou eletricidade.

c. Interpretação 2: ....sem esgotos, nem sequer eletricidade.

Acreditamos que o facto de esta partícula poder assumir diferentes valores dificulta uma identificação clara dos contextos em que ocorre como conjunção de coordenação. 


\section{Semelhanças e diferenças entre nem coordenativo e nem (sequer)}

A dificuldade de distinguir o nem coordenativo de nem (sequer) quando a partícula aparece em estruturas de coordenação leva-nos a colocar as seguintes questões:

(i) Que propriedades aproximam estas duas partículas?

(ii) Que propriedades as distinguem? Como diferenciá-las?

Nesta secção, refletiremos sobre o comportamento de nem em PE e mostraremos que há argumentos para sustentar a ideia de que existem duas partículas homónimas nem e que, apesar de haver aspetos comuns que as aproximam, é possível identificar um conjunto de propriedades que as distinguem.

\subsection{Semelhanças}

Um aspeto que aproxima o comportamento do nem coordenativo do comportamento de nem (sequer) reside no facto de ambos parecerem ser itens de polaridade negativa. Com efeito, como foi já referido atrás e como mostraremos novamente através dos dados que apresentaremos em seguida, em qualquer dos casos, a ocorrência desta partícula apenas é legítima em contextos negativos.

Assim, quando o nem corresponde a uma conjunção coordenativa, se ocorrer em posição pós-verbal, exige a presença de um elemento se negação pré-verbal, nomeadamente o marcador de negação frásica, o que dá origem aos contrastes que observamos em (19) e (20):

(19) a. *A Ana tomou nem café nem chá.

b. A Ana não tomou nem café nem chá.

(20) a. *O jornalista terminou a reportagem nem publicou as fotografias do evento.

b. O jornalista não terminou a reportagem nem publicou as fotografias do evento.

O mesmo acontece com nem não conjuncional, como se pode ver em (21):

(21) a. *Ele cumprimentou nem (sequer) o Primeiro Ministro.

b. Ele não cumprimentou nem (sequer) o Primeiro Ministro.

Por outro lado, também em ambos os casos, quando nem ocorre em posição pré-verbal, a sua presença tem o efeito de tornar a frase negativa ${ }^{6}$. Assim, observemos os dados apresentados em (22) e (23), que mostram que, nas expressões coordenadas correlativas, a presença do nem no primeiro termo coordenado torna a frase negativa, acontecendo o mesmo em (24) e em (25), com o nem marcador negativo:

(22) Nem a Ana nem a Maria tomaram chá.

(23) Nem o pároco nem a igreja local escaparam à tempestade de assaltos que aterroriza a Venda Nova. (par=ext1234072-soc-93a-1)

(24) ainda nem sequer é certo que vá ser construída uma nova fábrica

(par=ext61-eco-92a-1)

\footnotetext{
${ }^{6}$ Como veremos na secção 5, nas construções com nem não correlativo, é a primeira ocorrência de nem que legitima a conjunção coordenativa nem, o núcleo da estrutura coordenada, torna, a estrutura coordenada correlativa negativa.
} 
(25) "Você nem imagina as voltas que nós juízes damos à cabeça para tentar diminuir as penas..." (par=ext328728-soc-97a-2)

O facto de ambas as instâncias de nem apenas ocorrerem em domínios frásicos negativos, podendo, por isso, ser considerados itens de polaridade negativa intrínseca é, então, um aspeto que aproxima as partículas homónimas em estudo.

\subsection{Diferenças}

Apesar da semelhança notada na secção anterior, respeitante ao valor negativo das partículas nem, alguns argumentos empíricos podem ser apresentados para mostrar que o comportamento destas partículas não é uniforme e que é possível distinguir os contextos em que ocorre a conjunção coordenativa dos contextos em que ocorre nem não conjuncional.

Antes de mais, veja-se a possibilidade de ocorrência de nem (sequer) em frases em que não existe nenhuma estrutura de coordenação:

(26) a. A Liga nem sequer pode comprovar que de facto está a ser feito um inquérito. (par=ext311-soc-91b-1)

b. aqui devia ter logo terminado um problema que nem começara. (par=ext1096208-soc-96a-1)

Note-se, por outro lado, que, como está exemplificado em (27) e (28), nem sempre, nas frases com uma estrutura de coordenação, é possível a ocorrência do advérbio sequer, o que aponta, tal como o aspeto anterior, para uma diferente distribuição sintática da conjunção coordenativa e do item de negação nãoconjuncional, mostrando que se trata, efetivamente, de duas partículas homónimas e não de uma mesma unidade:

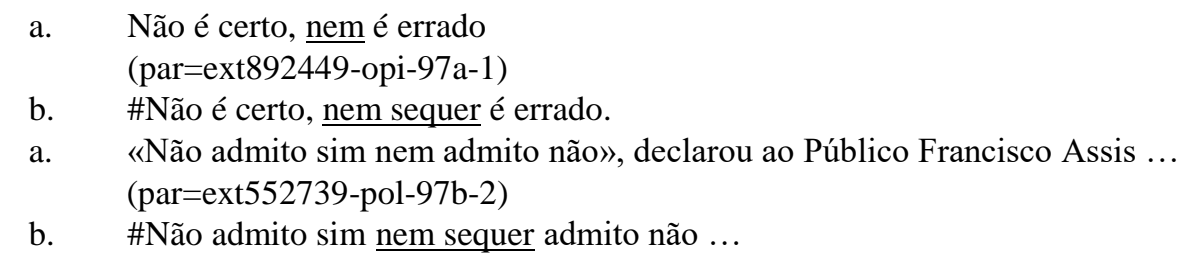

O aspeto ilustrado nos dados que apresentamos em (29) a (31) confirma esta ideia, mostrando a possibilidade (já notada em Oliveira 2011) de, em certos contextos, a partícula nem poder coocorrer com uma conjunção coordenativa. Esta possibilidade de coocorrência comprova que se trata de categorias distintas, o que conduz à conclusão de que, neste caso, nem não corresponde a uma conjunção coordenativa, mas sim a um elemento de negação nãoconjuncional:

(29) O problema é que ele é o único a apoiar a sua própria opinião e nem sequer nos consulta. (par=ext84840-pol-97a-1)

(30) Em cada álbum que fizemos há aspectos de que cada um de nós gosta menos, ou nem sequer gosta. (par=ext86476-clt-94b-2)

(31) Esta euforia sinalética parece indicar que dantes «Lire» era uma revista caótica, mas nem sequer é verdade. (par=ext78081-clt-92b-1) 
Contrariamente, nem coordenativo não pode coocorrer com outras conjunções coordenativas, no mesmo nível da coordenação, como se vê em (32)-(33):

(32) a. ??Não é certo e nem é errado.

b. *Não é certo ou nem é errado.

c. *Não é certo mas nem é errado. (33)

b. * Não admito sim ou nem admito não.

a. ??Não admito sim e nem admito não.

c. * Não admito sim mas nem admito não.

Confirmamos, pois, observando os dados, que existem duas partículas nem em PE, que apresentam uma distribuição sintática diferente e que são categorialmente distintas. Embora tenham em comum o facto de a sua ocorrência apenas ser possível em contextos negativos, a verdade é que o nem conjunção coordenativa se comporta de forma distinta do nem item de negação não conjuncional face a diversos aspetos.

\section{Nem (sequer) como partícula escalar}

De acordo com a literatura relevante, partículas como nem têm sido analisadas como itens escalares, além de itens de polaridade negativa. Os primeiros autores a analisar partículas escalares foram Horn (1969, 1970, 1972) e Fauconnier (1975a, b), que concluíram que algumas expressões têm a capacidade de criar interpretações de pontos máximos e mínimos de uma escala.

Também segundo o que é defendido por Gutiérrez-Rexach \& Schwenter (2001), as partículas escalares criam escalas pragmáticas e indicam que a proposição referida é menos esperada, ou mais inesperada, do que outras proposições localizadas na mesma escala. Em relação a estas escalas, Neubarth (2006) refere ainda que existem vários tipos de escalas: de quantidade, de especificidade, ou de probabilidade, sendo que as últimas ocorrem, tipicamente, ligadas a operadores de foco.

Assim, tendo em conta as caraterísticas das partículas escalares, assumimos que, em PE, o item de negação nem (sequer) apresenta um valor escalar, tal como acontece em espanhol com a expressão ni (siquiera). Bosque (1980), elaborando sobre Fauconnier (1975), analisa também ni siquiera como um termo de polaridade negativa que exibe um valor escalar pragmático-discursivo.

Para o espanhol atual, num estudo de análise de corpus, Albelda \& Gras (2011) mostram que, apesar de originalmente o valor escalar decorrer da presença de siquiera, $n i$ isolado com valor escalar apresenta maior frequência do que ni siquiera, estando ambos ilustrados em (34):

(34) a. Ni siquiera el Dr. Rodriguez de la Fuente sabía si los lobos sueñam. (Bosque 1980: 110)

b. No vino Pablo, y ni avisó.

(Albelda \& Gras 2011)

Portolés (2007) e, na sua esteira, Albelda \& Gras (2011) correlacionam o valor escalar de ni com um valor de focalização (cf. Neubarth, 2006): do ponto de vista pragmático-discursivo, o marcador negativo ni cria uma escala negativa de probabilidades, situando o elemento focalizado no ponto mais alto dessa escala. Esta propriedade permite distinguir o $n i$ escalar do $n i$ coordenativo, que coordena elementos, não os colocando em diferentes pontos numa escala. ${ }^{7}$

\footnotetext{
${ }^{7}$ Um revisor de uma versão anterior deste texto chamou a atenção para o facto de o nem conjuncional estar associado a um valor que, de certa forma, pode também ser considerado escalar. No entanto, neste artigo, assumimos uma definição de escala que parte da existência de diferentes níveis, neste caso, de probabilidade, e da colocação de uma entidade num ponto máximo que acontece por efeito da ocorrência de nem (sequer), ou seja, do nem não conjuncional. O efeito de distinção de diferentes níveis numa escala e de colocação de uma entidade num nível máximo não é obtido através da ocorrência do nem conjuncional.
} 
Tomando um exemplo como (35), para o PE, percebemos que a frase não transmite apenas a informação de que o Pedro não fez o trabalho. A inclusão da partícula escalar nem indica-nos também que o Pedro era a pessoa que mais provavelmente faria o trabalho, assim, retomando a definição de Gutiérrez-Rexach \& Schwenter (2001), o Pedro não fazer o trabalho seria a proposição mais inesperada.

(35) Nem o Pedro fez o trabalho.

(36) Representação esquemática da interpretação escalar de (35):

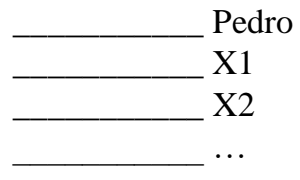

Assim, e de acordo com Aranovich (2007), que refere que estes elementos são usados para negar a existência de alternativas num modelo escalar, a interpretação escalar implica que, se o Pedro não fez o trabalho, o mesmo acontece com todas as alternativas que se encontram (abaixo) na mesma escala (X1, X2, etc), ou seja, a possibilidade de alternativas na escala é negada. Para este autor, o traço característico destes itens é, então, o de denial (negação).

Tendo em conta a literatura existente, principalmente para o espanhol, assumimos que, em PE, a atribuição de um valor escalar a nem decorre, essencialmente, de fatores pragmáticos e discursivos.

\section{Legitimação de nem coordenativo em estruturas de coordenação integrada}

Centrando-nos nas ocorrências de nem em construções que envolvem coordenação, procuraremos nas secções 5 e 6 dar conta da sua legitimação, respetivamente em estruturas coordenadas integradas e em estruturas de coordenação parentética.

Como vimos na secção 4.1, nem coordenativo é um item de polaridade negativa, ou seja, só pode ocorrer em domínios negativos. Em línguas como o português europeu, o italiano e o espanhol, a negação no domínio frásico tem de ter escopo em sintaxe sobre o verbo afetado pelas marcas de tempo verbal que ocorre em T(empo); consequentemente, nestas línguas, o marcador de negação frásica precede o verbo (e.g. Zanuttini 1991, 1997; e para o português, Matos 2001, Peres 2013) (37a). Nas referidas línguas, quando os itens de polaridade negativa intrínseca precedem e c-comandam ${ }^{8}$ o verbo, negam a frase e não, marcador de negação frásica, não pode ocorrer, como mostra (37b). Porém, quando os itens de polaridade negativa surgem em posição pós-verbal, a presença do marcador de negação frásica é requerida, como ilustrado em (37c) vs. (37d):

(37) a. Ela não tomou café.

b. Ninguém (*não) tomou café.

c. Não tomou ninguém café.

d. *Tomou ninguém café.

\footnotetext{
8 (i) C-comando

$\mathrm{X}$ comanda $\mathrm{Y}$ se são dominados pela mesma categoria

e Y é nó irmão de $\mathrm{X}$, ou está contido num nó irmão de $\mathrm{X}$.
} 
O comportamento de nem coordenativo nas estruturas coordenadas correlativas é, aparentemente, idêntico ao dos itens de polaridade negativa. Consideraremos, em primeiro lugar. As estruturas coordenadas correlativas e em segundo lugar os casos em que ocorre nem simples (não correlativo).

Como mostram as estruturas coordenadas correlativas, em posição pré-verbal, o constituinte instanciado por nem...nem é, por si só, suficiente para negar a frase e não é compatível com o marcador de negação frásica (veja-se (38a) e (38b)). No entanto, quando nem..nem ocorre em posição pós-verbal, a presença do marcador de negação frásica é necessária (veja-se (38c)).

(38) a. Nem a Ana nem o Pedro tomaram chá.

b. *Nem a Ana nem o Pedro não tomaram chá.

c. A Ana * $(\underline{\text { não}})$ tomou [nem café nem chá].

d. *A Ana nem o Pedro tomaram chá.

Adicionalmente, exemplos como (38d) mostram que na locução correlativa nem..nem, apenas o último nem funciona como conjunção coordenativa. À primeira ocorrência de nem está reservado o papel de marcar o início da estrutura coordenativa e de atribuir valor negativo a nem conjuncional, tornando negativa toda a estrutura correlativa9.

Assim, em (38a), o constituinte coordenado negativo tem escopo sobre o verbo em T(empo), como se pode observar na representação que apresentamos em (39).

(39)

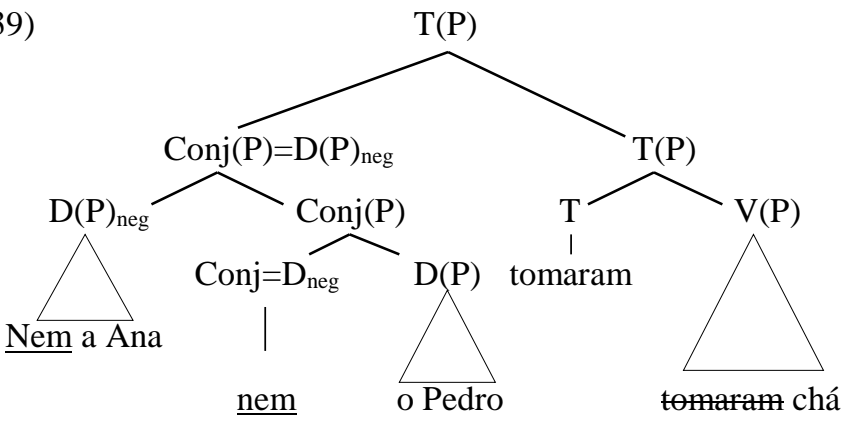

Em (39), em conformidade com o Programa Minimalista, adota-se a proposta da Estrutura Sintagmática Nua (Bare Phrase Structure), de acordo com a qual a natureza categorial dos objetos sintáticos compostos construídos pela operação de Compor (Merge) é idêntica à dos seus núcleos provenientes do léxico, as únicas categorias com conteúdo interpretável na componente semântica; assim, as projeções máximas sintagmáticas não se distinguem essencialmente dos seus núcleos, T, V, Conj ou D.

Adicionalmente, em (39), adotamos a proposta clássica de que a conjunção coordenativa, Conj, é um núcleo funcional subespecificado que assume, por Concordância (Agree), a natureza categorial do primeiro termo coordenado (cf. Johannessen, 1998; Colaço 1999, e.o.) e que essa concordância envolve igualmente os

\footnotetext{
${ }^{9}$ Evidência para que apenas o segundo termo da expressão coordenativa correlativa é que funciona como conjunção é fornecido por outras locuções, como, por exemplo, tanto ... como, não só ... mas (também/ainda).
} 
Assim, em (38a), como ilustrado em (39), o constituinte negativo nem a Ana nem o Pedro c-comanda o verbo em T(empo). O mesmo não sucede em (38c), em que o constituinte negativo ocupa uma posição estrutural mais baixa.

Note-se que nem simples (i.e., não-correlativo) não pode por si só assegurar o valor negativo do constituinte que coordena, mesmo que ocorra em posição inicial de frase, como mostra a agramaticalidade do seguinte exemplo:

(40) *A Ana nem o Pedro tomaram chá.

Este facto é explicável tendo em conta o estatuto desta ocorrência de nem na estrutura coordenada. Enquanto núcleo conjuncional coordenativo, com traços subespecificados, nem tem de ser legitimado por concordância com o primeiro termo coordenado, em (40) a Ana. Porém, este constituinte não exibe quaisquer traços negativos que fixem os traços subespecificados de negação desta conjunção.

Assim, confrontando nem simples com nem correlativo (nem...nem), admitimos que, no caso deste último, apenas a segunda ocorrência de nem é uma conjunção e que o nem inicial é um item de polaridade negativa intrínseca, que funciona como as chamadas palavras-N em português europeu (e.g., ninguém, nada, ...). ${ }^{10}$

As frases coordenadas pela conjunção simples nem exibem um padrão típico da coordenação negativa não-correlativa e exigem que o primeiro termo da coordenação frásica seja negativo (cf. (41)):

(41) a. O jornalista não terminou a reportagem nem o fotógrafo disponibilizou as fotos. b. *O jornalista terminou a reportagem nem o fotógrafo disponibilizou as fotos.

Porém, diferentemente do que acontecia em (38a), o marcador de negação frásica, que, neste caso, ocorre no interior do primeiro termo coordenado, não c-comanda nem, como mostra a representação que apresentamos em (42), em que é assumida a proposta de Pollock (1989) para a negação frásica. Assim, para explicar os contrastes em (41), uma proposta alternativa tem de ser encontrada.

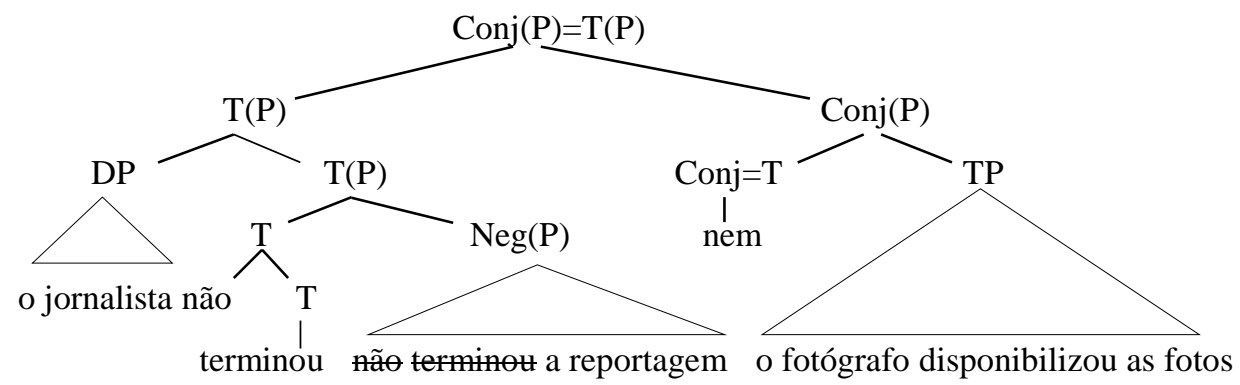

Admitimos que, no quadro Minimalista atual (Chomsky, 2013, 2015), é possível dar conta destes casos. Neste quadro de referência, o esqueleto estrutural das frases é construído, em conformidade com a Estrutura Sintagmática Nua, pela operação de Compor (Merge) e o mecanismo de Etiquetagem.

\footnotetext{
${ }^{10}$ Esta posição é compatível com o facto nem não-conjuncional na expressão nem-sequer não poder ser legitimado pela conjunção nem quando ocorre isolada (i), mas poder sê-lo, ainda que enfaticamente, pelo correlativo nem ...nem (cf. (ii)

(i) *O jornalista nem nem sequer o fotógrafo se deslocaram ao local.

(ii) Nem o jornalista nem NEM SEQUER o fotógrafo se deslocaram ao local.
} 
Como vimos, de acordo com a Estrutura Sintagmática Nua, os objetos sintáticos exibem a natureza categorial dos itens provenientes do léxico. A distinção entre categorias núcleo e projeções máximas decorre da posição sintática que ocupam: são interpretadas como projeções máximas todas as categorias que não são núcleo. Por sua vez, o mecanismo de Etiquetagem atribui a cada uma dessas projeções os traços do seu núcleo.

Assumimos que não, o núcleo de Neg, por Compor Interno (i.e., por movimento), forma com T um núcleo complexo, T_Neg ${ }^{11}$. Pelo mecanismo de Etiquetagem, esse núcleo temporal negativo é assumido como a etiqueta do constituinte sintático que projeta, $\mathrm{T}_{\mathrm{Neg}}(\mathrm{P})$, como se pode observar em $(43)^{12}$ :

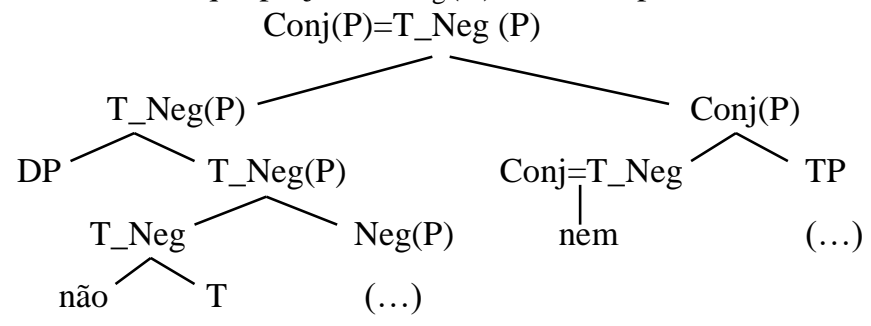

Em (43), o primeiro termo coordenado é etiquetado como negativo, devido à natureza negativa do seu núcleo, o marcador de negação frásica. Este $T_{-} N e g(P)$ não só c-comanda Conj, legitimando nem, como concorda em traços categoriais e negativos com o núcleo Conj, convertendo toda a estrutura coordenada, i.e. de ConjP, numa coordenação de frases negativas, $\operatorname{Conj}(\mathrm{P})=\mathrm{T} \_\mathrm{Neg}(\mathrm{P})^{13}$.

Em suma: nem enquanto conjunção coordenativa tem traços categoriais e de polaridade negativa que devem ser fixados sob c-comando por um constituinte negativo ${ }^{14}$, prototipicamente o termo coordenado negativo que estabelece a relação de Concordância com a conjunção coordenativa. Por sua vez, na construção correlativa, a primeira instância de nem não é uma conjunção, mas um operador de polaridade negativa intrínseca que tem de ocorrer num domínio frásico negativo: quando c-comanda o núcleo T, o constituinte que ele encabeça torna a frase negativa; quando ocorre no domínio frásico abaixo de $\mathrm{T}$, requer a presença de um constituinte negativo que tenha escopo sobre $\mathrm{T}$.

\section{Legitimação de nem coordenativo em estruturas de coordenação não integrada}

Nem conjunção coordenativa pode ocorrer no interior de expressões parentéticas. Porém, o marcador de negação, que, como se viu, é necessariamente requerido, pode ocorrer no interior da frase hospedeira. É o que se verifica nos dados que apresentamos em (44):

(44) a. O único senão deste conto de fadas é que Nelson Mandela não confirmou - nem desmentiu - que o casamento se realiza hoje. (par=ext21938-pol-98b-2)

b. ... *Mandela confirmou - nem desmentiu - que o casamento se realiza hoje.

\footnotetext{
${ }^{11}$ Constitui evidência para a formação desse complexo o facto de, em contextos de movimento de T para C, o marcador de negação frásica não se poder dissociar do verbo em $\mathrm{T}$ :

(i) Não tivesse ela estado incessantemente a trabalhar e as coisas seriam bem piores.

12 Note-se que, em termos de c-comando do marcador de negação, outras alternativas de representação da estrutura da negação frásica se comportariam de forma idêntica. Assim, no caso de se considerar que, em línguas como o português, Neg dominaria T e não o inverso (cf. Zanuttini 1997), teríamos uma representação como (i), em que não, o núcleo de Neg(P), não c-comanda nem:

(i) $\left[\mathrm{ConjP}_{\mathrm{Neg}(\mathrm{P})} \mathrm{XP}[\mathrm{Neg}\right.$ ão] TP] [ [ Conjnem] TP $\left.\left.]\right]\right]$

${ }^{13} \mathrm{O}$ mesmo resultado seria obtido se assumíssemos a proposta de que o nó mais cimeiro da frase negativa em português era Neg(P) e não $\mathrm{T}(\mathrm{P})$.

${ }^{14}$ Note-se que, em exemplos como (i), em que nem não-correlativo ocorre em posição pós-verbal, a fixação dos traços negativos da conjunção é feita sob c-comando:

(i) A Ana não tomou café nem chá.
} 
No entanto, a construção de uma estrutura parentética resulta de Parenthetical Merge, uma operação que, de acordo com vários autores (cf. de Vries, 2012; Colaço \& Matos, 2016), bloqueia o c-comando por parte da frase hospedeira. O contraste entre (45a) e (45b) ilustra esta propriedade, mostrando a ausência de efeitos de Princípio $\mathrm{C}$ em frases em que a coordenação é parentética, contrariamente ao que acontece em frases com coordenação integrada ${ }^{15}$ :

(45) a. Ela $a_{i}$ não prometeu - nem a Maria $a_{i}$ podia prometer tal coisa - fazer o trabalho.

b. ??/*Ela $\mathrm{i}_{\mathrm{i}}$ não fez o trabalho nem a Maria $\mathrm{i}_{\mathrm{i}}$ prometeu fazê-lo.

Uma vez que o c-comando por parte da hospedeira relativamente à parentética é bloqueado, a relação de concordância local entre a frase hospedeira negativa e a conjunção nem na parentética está inviabilizada. Exemplos como (46), em que ocorre a expressão correlativa nem ...nem, que requer estrita localidade entre os termos coordenados, mostram que o bloqueio de c-comando impede a concordância local:

(46) *Mandela nem confirmou - nem desmentiu - que o casamento se realiza hoje.

Deste modo, para dar conta dos contrastes em (44), adotamos a proposta de Colaço e Matos (2010) de que a coordenação parentética corresponde a uma estrutura de elipse do primeiro termo coordenado, e que o seu apagamento é legitimado sob identidade relativamente ao constituinte âncora. Assim sendo, a legitimação do item de polaridade negativa é assegurada pela presença de um marcador de negação no constituinte elidido.

Esta hipótese permite igualmente explicar a possibilidade da ocorrência de nem coordenativo a iniciar um fragmento de discurso autónomo daquele em que ocorre o marcador de negação que o legitima (cf. Colaço, 2013):

(47) Mandela não confirmou que o casamento se realiza hoje. Nem desmentiu.

Note-se que estas possibilidades se estendem a itens de polaridade negativa pós-verbais, cuja ocorrência é igualmente possível em expressões parentéticas e em fragmentos discursivos autónomos, como se pode observar, respetivamente, em (48) e (49):

(48) O Pedro não contou aos amigos - e a ninguém da família - o que aconteceu naquela tarde.

(49) O Pedro não contou aos amigos o que aconteceu naquela tarde. E a ninguém da família.

\section{Conclusões}

Neste estudo, procedemos, num primeiro momento, ao confronto entre nem conjunção coordenativa e nem não conjuncional que pode coocorrer com sequer. Mostrámos que se trata de duas partículas homónimas que, embora partilhem o facto de ocorrerem necessariamente em domínios negativos, exibem várias propriedades que as distinguem entre si, discursiva e sintaticamente. Destacámos, entre elas, que o nem não conjuncional pode ocorrer em domínios não coordenados e, do ponto de vista discursivo, apresenta uma natureza escalar, eventualmente decorrente do seu valor de focalização.

\footnotetext{
${ }^{15}$ Como foi notado por um revisor, neste caso, pelas razões mencionadas atrás, a primeira ocorrência de nem, só por si, não seria legítima enquanto elemento coordenativo.
} 
Centrando-nos nos casos em que nem é uma conjunção coordenativa, apresentámos uma proposta de análise das construções que envolvem coordenação integrada e não integrada.

Nas estruturas de coordenação integrada, nem pode corresponder a uma conjunção simples ou correlativa. No que diz respeito à conjunção correlativa nem...nem, quando o constituinte que integra ocorre em posição pré-verbal, é, por si só, suficiente para negar a frase. Este facto foi explicado recorrendo à assunção de que a primeira instância de nem no primeiro termo coordenado funciona como um item de polaridade negativa intrínseca que torna Conj(P) negativo, e permite que este último constituinte ao c-comandar o núcleo $\mathrm{T}$, torne $\mathrm{T}(\mathrm{P})$ um domínio negativo. Contrariamente, quando ocorre em posição pós-verbal, o constituinte que integra a conjunção correlativa tem de ser legitimado por um constituinte negativo que tenha escopo sobre $\mathrm{T}$ e, dessa forma, converta $\mathrm{T}(\mathrm{P})$ num domínio negativo. Relativamente à conjunção nem simples, a sua legitimação decorre necessariamente da presença de um constituinte negativo, nomeadamente o marcador de negação frásica. Quando a coordenação é oracional, o marcador de negação frásica no interior do primeiro termo coordenado não c-comanda a conjunção nem. Assumimos que o marcador de negação forma com $\mathrm{T}$ um núcleo negativo, o que faz com que o primeiro termo coordenado, $\mathrm{T}(\mathrm{P})$, seja um constituinte negativo que c-comanda e legitima nem.

O desafio levantado pela possibilidade de ocorrência da conjunção nem em estruturas de coordenação não integrada - nomeadamente, em estruturas parentéticas e em estruturas em que a sequência iniciada pela conjunção constitui um fragmento discursivo autónomo - foi explicada recorrendo à ideia de que estas construções envolvem a elipse do primeiro termo coordenado.

\section{Referências}

Albelda, M. \& P. Gras (2011) La partícula escalar ni en español coloquial. In R. Gonzalez Ruiz \& C. Llamas Saiz (eds.), Gramatica y discurso. Nuevas aportaciones sobre particulas discursivas del espanol. Pamplona: EUNSA.

Aranovich, R. (2007) Negative polarity and scalar semantics in Spanish. Lingvisticae Investigationes 30(2), pp. $181-216$.

Bosque, I. (1980) Sobre la Negacion. Madrid: Catedra.

Chomsky, N. (1995) The Minimalist Program. Cambridge, MA: MIT Press.

Chomsky, N. (2013) Problems of Projection. Lingua, 130, pp. 33-49.

Chomsky, N. (2015) Problems of projection: extension. In E. Domenico, C. Hamann, S. Matteini (eds). Structures, Strategies and Beyond - Studies in Honour of Adriana Belletti. Amsterdam/Pliladelphia: Jonh Benjamins, pp. 3-16.

Colaço, M. (1999) Concordância parcial em estruturas coordenadas em Português Europeu. Actas do XIV Encontro da Associação Portuguesa de Linguística, vol.I, pp. 349-368

Colaço, M. \& G. Matos (2010) Estruturas coordenadas sem especificador realizado em português europeu. Diacrítica 24(1), pp. 267-288.

Colaço, M. (2013) Coordenação e fronteiras discursivas. In F. Silva, I. Falé \& I. Pereira (eds) Textos Seleccionados do XXVIII Encontro Nacional da Associação Portuguesa de Linguística 2012. Lisboa: APL Textos, pp. 249-269.

Colaço, M. \& G. Matos (2011) Construções parentéticas coordenadas ancoradas oracionais e sintagmáticas. In Brito, A. Ma., F. Silva, J. Veloso \& A. Fiéis (orgs). Textos seleccionados do XXVI Encontro Nacional da Associação Portuguesa de Linguística 2010. Lisboa: APL, pp. 182-196.

Colaço, M. \& G. Matos (2016) Explicative clauses in portuguese as a case of parentheses. In Alexandra Fiéis, Maria Lobo \& Sandra Pereira (eds.), Romance languages and Linguistic Theory: Selected papers from Going Romance 28. Amesterdam/ Philadelphia: John Benjamins, pp. 43-60. 
Fauconnier, G. (1975a) Pragmatic Scales and Logical Structure. Linguistic Inquiry 6 (3), pp. 353-375.

Fauconnier, G. (1975b) Polarity and the scale principle. CLS 11, pp. 188-99.

Gutiérrez-Rexach, J. \& S. Schwenter (2001) A scalar propositional negative polarity item in Spanish. In R. Núñez-Cedeño, L. López \& R. Cameron. A Romance perspective on language knowledge and use. Amesterdam/Philadelphia: John Benjamins, pp. 119-131.

Horn, L. (1969) A Presuppositional Analysis of only and even. In R. I. Binnick et al., (eds). Papers of the Fith Regional Meeting of the Chicago Linguistics Society, pp. 98-107.

Horn, L. (1970) Ain't it hard (anymore). Papers from the 6th Regional Meeting of the Chicago Linguistic Society, Chicago: Chicago Linguist. Soc, pp. 318-27.

Horn, L. (1972) On the Semantic Properties of Logical Operators in English, unpublished Doctoral dissertation, UCLA, Los Angeles, California. Johannessen, J. (1998) Coordination, Oxford, Oxford University Press

Matos, Gabriela (2001) Negative Concord and the Minimalist Approach. In D’Hulst, Yves, Johan Rooryck and Jan Shroten (eds.), Romance Languages and Linguistic Theory 1999. Amsterdam \& Philadelphia: John Benjamins, pp. 245-280.

Matos, G. (2003a) Estruturas de coordenação. In Mateus, M. H., et al. Gramática da Língua Portuguesa. Lisboa: Caminho, pp. 549-592.

Matos, G. (2003b) Aspetos sintácticos da Negação. In Mateus, M. H., et al. Gramática da Língua Portuguesa. Lisboa: Caminho, pp. 767-793.

Matos, G. \& M. Colaço (2011) Floating parenthetical coordinate clauses. In Berns, Janine, Haike Jacobs \& Tobias Sheer (eds.) Romance Languages and Linguistic Theory 2009, Amsterdam \& Philadelphia: John Benjamins Publishing Company, pp. 203-221.

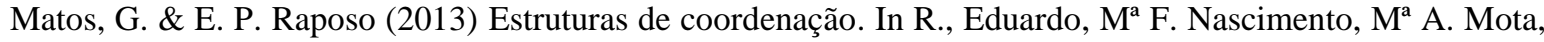
L. Segura \& A. Mendes (orgs.) Gramática do Português, vol. II, cap. 35, Lisboa: Fundação Calouste Gulbenkian, pp. 1761-1817.

Neubarth, F. (2006) Polarity, Alternatives, and Scales. Dissertação de doutoramento. Universidade de Viena.

Oliveira, Ma . C. (2011) A sintaxe da coordenação e os conectores conclusivos. Dissertação de doutoramento. FLUP.

Peres, João (2013) Negação. In R., Eduardo, Mª F. Nascimento, Mª A. Mota, L. Segura \& A. Mendes (orgs.) Gramática do Português, vol. I, cap. 14, Lisboa: Fundação Calouste Gulbenkian, pp. 459-498.

Pollock, J.-Y. (1989) Verb Movement, UG and the Structure of IP, Linguistic Inquiry, 20, pp. $365-424$.

Portoles Lazaro, Jose (2007) Las escalas informativas convocadas por 'ni' y 'ni siquiera'. Revista Internacional de Linguistica 10, pp. 199-220.

Vries, M. (2012) Unconventional Mergers. In M. Uribe-Etxebarria and V. Valmala (eds.) Ways of Structure Building, Oxford: Oxford University Press, pp. 143-166. doi: 10.1093/acprof:oso/9780199644933.003.0007

Zanuttini, R. (1991) Syntactic Properties of Sentential Negation. A Comparative Study of Romance Languages. PhD Dissertation. University of Pennsylvania.

Zanuttini, R. (1997) Negation and Clausal Structure - a Comparative Study of Romance Languages. New York, Oxford: Oxford University Press.

CETEMPúblico 1.7 v.7.7, disponível em: https://www.linguateca.pt/CETEMPublico/ (corpus organizado por D. Santos) 